Article

\title{
Before Landing: How Do New European Emigrants Prepare Their Departure and Imagine Their Destinations?
}

\author{
Diego Coletto * and Giovanna Fullin \\ Department of Sociology and Social Research, University of Milano-Bicocca, 20126 Milano, Italy; \\ E-Mails: diego.coletto@unimib.it (D.C.), giovanna.fullin@unimib.it (G.F.) \\ * Corresponding author
}

Submitted: 23 July 2019 | Accepted: 10 September | Published: 7 November 2019

\begin{abstract}
In migration studies, the preparation for the departure of people who decide to migrate has seldom been addressed as a distinct topic. This article aims at investigating how European migrants who moved or plan to move to another European country prepare their departure. It analyses stories of migrants who move from Italy, Spain, Romania, and Bulgaria. More specifically, attention is focused on departure preparation in order to investigate what migrants do before they depart and how the free mobility of work is perceived by Europeans and applied to their migration plans. Different from general statements about European integration and belonging or about obstacles to intra-EU mobility, the analysis of what individuals do in order to get ready to leave their country of origin provides a very realistic idea of how people perceive European Union and the mobility within it.
\end{abstract}

\section{Keywords}

European Union; imaginaries; integration; migration; social media

Issue

This article is part of the issue "The Lived Experiences of Migration: Individual Strategies, Institutional Settings and Destination Effects in the European Mobility Process" edited by Neli Demireva (University of Essex, UK) and Fabio Quassoli (University of Milano-Bicocca, Italy).

(C) 2019 by the authors; licensee Cogitatio (Lisbon, Portugal). This article is licensed under a Creative Commons Attribution 4.0 International License (CC BY).

\section{Introduction}

In migration studies, the preparation for the departure of people who decide to migrate has seldom been addressed as a distinct topic. Scholars' attention focused more, on the one hand, on factors explaining the decision to migrate and, on the other, on the outcomes of migration in terms of settlement in the destination country, integration/segregation in the labour market and so on. Both of these topics are addressed by other articles on this issue, investigating the motivations of the decision to migrate, which precedes the preparation phase, and the consequences of that decision, i.e., the arrival in the destination country, the search for accommodation and a job, and the integration process. Our contribution aims at providing an explorative analysis of the phase that is between these two.
The preparation phase, which includes all the activities that migrants put in place before leaving their country in order to move abroad, is worth investigating as it can provide an interesting insight into the lived experiences of migration. What people do (and what they do not) once they have decided to migrate in order to get ready to leave their origin country can highlight how they imagine the migration process and what difficulties they expect to meet. Moreover, we believe that this specific phase-during which prospective migrants start to face their decision to migrate-can be an interesting 'policy field.' Indeed, policies can intervene in order both to ease the processes of information collection and to support prospective migrants to fill possible gaps in terms of competences or skills. Besides the focus on the particular phase of preparation to migrate, our analysis differs from the existing literature for another reason. It takes into 
consideration European migrants who moved or plan to move to another European country, while the few pieces of literature concerning the preparation for departure mainly refer to migrants moving without regular documents and the channels through which migration is perpetuated (for instance, King, 2012; Massey et al., 1998; Menjìvar, 2000; Portes \& Sensenbrenner, 1993).

Actually, there has been less attention on the preparation of migrants who move without constraints arising from their legal status, as Europeans moving within the European Union (EU). Intra-EU mobility has been often depicted as very different from traditional migration: easier, fluid, and easily reversible thanks to the geographical proximity and the freedom of movement across European countries. The preparation process for departure is worth studying, particularly with regard to this type of migration. Different from general statements about European integration and belonging or about obstacles to intra-EU mobility, the analysis of how people who decided to move abroad prepare their departure provides a very realistic idea of how the free mobility of work is perceived by Europeans and how it is applied to their migration plans. The research analyses the stories of migrants who moved or planned to move from Italy, Spain, Romania and Bulgaria. Given that all the four countries have been deeply hit by the 2008 economic crisis and saw an increasing number of young people moving abroad, a better understanding of these migrations is crucial and can provide suggestions for policies.

After having presented the theoretical framework (Section 2) and research questions and method (Section 3), we will show findings concerning preparation to migrate (Section 4). Some concluding remarks and policy implications will close the article.

\section{The Theoretical Background}

Given the lack of studies on the specific phase of preparation to migrate, we built our theoretical background by referring to the literature on intra-EU migrations and on the factors affecting the decision to move abroad, focusing on those that can help to explain the preparatory steps.

The recent intra-EU migrations have been depicted by some scholars as a form of geographical mobility that is quite different from traditional migrations. Some pieces of research show a quite enthusiastic approach and depict the migration of high-skilled workers as a part of the contemporary globalisation process, whereby highly-educated people can move across interconnected societies to pursue better careers, personal aspirations and lifestyle choices (Favell, 2008; Favell \& Recchi, 2009). According to King (2018), this literature approach is often characterised by a too-celebratory, self-referential rhetoric of the 'Erasmus generation.' Beyond the literature debate, it is true that the new geographical mobility across European countries have some features that both the past intra-EU migratory movements and the recent international migrations did not have (Favell \& Recchi, 2009; Recchi, 2013; Smith \& Favell, 2006). First, European citizens are free to move across EU member countries: They do not need permits to stay or work (with some exceptions concerning new member states in the entry phase). This undoubtedly makes their geographical mobility much easier compared to the mobility of other migrants. Second, besides economic migrants, intra-EU mobility also concerns people moving for other reasons, such as professional self-fulfilment and country reputation, especially regarding labour market prospects in terms of openness and meritocracy (Bartolini, Gropas, \& Triandafyllidou, 2017). Third, people moving across Europe are often highly educated and their decisions to migrate entail fewer risks than for their non-EU counterparts concerning the trip, border crossing, and segregation in ethnic niches and informal low-skilled jobs upon arrival in the destination country (Recchi, 2013). Fourth, social media offers access to information about the destination country at little cost, through the revival of latent ties or the creation of new contacts (Dekker \& Engbersen, 2012; Haythornthwaite, 2002).

A literature stream has developed the idea of fluid or 'liquid migration,' applying Bauman's (2000) idea of liquidity to the new migration processes. In particular, new intra-European youth mobility is often perceived and described by migrants as 'reversible' short-term mobility (Engbersen, 2012). However, there is a harsher, darker side to the new intra-European youth migration. Indeed, within the European area, some differences between countries are worth considering, in particular after 2004, when eight Central and Eastern European countries joined the EU, followed by Bulgaria and Romania in 2007 and Croatia in 2013.

With the EU becoming bigger, the divide between dependent and escalator regions becomes clearer and mobility across them has confirmed these internal differences. Some cities-such as Berlin and London-have attracted huge migratory inflows from other European countries (and from outside EU) and East-West migrations have been strongly increasing. Our research, considering migrants going to Germany and the UK from Italy, Spain, Bulgaria and Romania and from the latter two countries to Italy and Spain, focuses exactly on such flows. According to the literature, for many workers from the East European countries, far from the life-style motivations just highlighted, migratory life in the 'West' has basically become practices of pure human survival, living on low wages, and doing tough jobs in degrading conditions (Castellani, 2018; King, 2018).

Furthermore, the 2008 economic crisis has pushed job seekers leaving South European countries to face their rising unemployment (Bartolini et al., 2017; Dimitriadis, Fullin, \& Fischer-Souan, 2019). The research focusing on these intra-EU movements reminds us of their similarities with traditional economic migrations. Castellani (2018), for instance, investigated the conditions of Italians and Spaniards in Berlin and showed 
that they often have low-skilled jobs even if they have a medium/high level of education. Several obstacles made their integration in the destination labour market difficult and explain downgrading trajectories: from the recognition of education titles and the requirements of specific professional bodies that regulate several high and low-skill occupations, to the inadequate knowledge of the local language.

Dimitriadis et al. (2019) found similar results. Moreover, national welfare systems can leave people coming from other European countries without some basic social protections, despite their European citizenship (Lillie \& Simola, 2016). What was seldom investigated is whether new intra-EU migrants are aware of the difficulties they have to face and try to prepare their departure accordingly or, on the contrary, whether they perceive their migration as a smooth process that does not require any special groundwork.

Once people decide to migrate, they also have to define where to go. Expectations and social imaginaries about the destination countries play a relevant role in this regard (Pessar \& Mahler, 2002). When analysing the preparation for the departure of migrants it is worth referring to the literature that investigated the social imaginaries and, in particular, that focused on those concerning places of departure/destination.

The concept of social imaginary has been widely debated in sociology. Various authors have referred to social imaginary as the way in which a given group of people imagines and narrates their life and the social reality in which they live (Castoriadis, 1997; O'Reilly, 2014). Social imaginary operates through the construction of meanings and, in particular, of myths, legends and shared narratives. According to this perspective, it can only exist if it is socially shared. Moreover, social imaginary is not necessarily a reflection of reality, nor is it totally the result of imagination, but rather it is a set of meanings shared by a community. The construction of social imaginaries is thus closely linked to institutions, to the set of shared values, to the cultural aspects that characterise a particular community and that contribute to defining how individuals perceive and understand the society they belong to (Taylor, 2004) and how they act (Benson, 2012). The approach of Appadurai (1996) is instead different, interpreting social imagination as an everyday practice that is constantly 'at work.' This approach highlights the role that the imaginary plays in consolidating and strengthening the agency of each individual. According to Appadurai, it is only thanks to the ability to imagine alternative futures that individuals become capable of making decisions and changing their lives. Hence, from literature emerges a tension between institutional factors, cultural framework and individual agency in the construction processes of social imaginaries that contribute to the social construction of reality.

In the migration studies domain, some authors have analysed how the interaction between shared social representations and individual imaginations has become an important factor in the processes concerning migration decisions at the global level (Benson, 2012). These processes of collective imaginaries' construction, although strongly 'embedded' in specific socio-economic contexts, are often 'enhanced' and conveyed by multiple communication channels, allowing a transnational diffusion. In this regard, Abrutyn and Mueller (2014) have revisited the social theories of Gabriel Tarde (2010)-who provided a first analysis of the spread of emotions, attitudes, and behaviour in society-highlighting how the concept of contagion could be relevant in order to explain migrations. Specifically, the concept of contagion was used to highlight how decisions to migrate could be affected by the fact that 'other people' migrated or by media's discourse about people leaving their home country. Indeed, the increasing use of social media seems to have widened the 'contagion' effect. New technologies mediate social life and migrants take advantage of them to shorten distances and build new ways of relating, both with the destination community and with their community of origin after leaving their home country. As Mapelli (2019, p. 14) wrote, social media "become virtual spaces in which some groups can create a feeling of community belonging." Salazar (2011) has instead highlighted how collective imaginaries related to migratory processes can become 'creative acts,' capable of improving the mobility capacities of people who live in disadvantaged situations in economic and power terms. These creative actions, which allow people to imagine themselves abroad, testify to the presence of individual agency even in situations characterised by evident institutional constraints and socio-economic disadvantages.

As far as social imaginaries relevantly affect the decision to migrate, they can also play a relevant role in the preparation phase, when people take (or should take) the first steps to approach their destination. Some research has highlighted how specific social imaginaries contribute to making a particular place a desirable destination for some social groups (Benson, 2012; Benson \& Osbaldiston, 2014). In this case, we are dealing with collective imaginaries that derive from a variable articulation of cultural factors, narratives, shared meanings and contingent aspects. These factors interact with individual factors, i.e., the experience of those who have already completed the migration process, which helps to strengthen or modify the prevailing imaginaries. The appropriation of these kinds of collective imaginary thus becomes an important element to explain the selection of a specific destination and how people approach it.

Concerning the latter point, some collective imaginaries are focused on specific cities, which are represented as places where, for various reasons, migrants can 'easily' achieve better working and life conditions (Benson \& O'Reilly, 2009). Moreover, as Maile and Griffiths (2012, p. 31) showed in their empirical research on Berlin, "the idea of quality of life is also overlaid by an array of imaginary and emotional investments which are rooted in individual biography and personal experi- 
ence." More generally, the two authors pointed out that both Berlin and London-cities that are lived in but also 'imagined'-become:

The repositories for a range of ambiguous emotional states. The issue....is what a city represents, or comes to represent, for individuals at particular points in time. Economic factors play a role but are mediated by an imaginative engagement with the city in which relationships and change in lifestyle are particularly significant. (Maile \& Griffiths, 2012, p. 48)

\section{Research Aims and Method}

This article investigates how European migrants, who moved or plan to move to another European country, prepare their departure. It draws on data from a Horizon 2020-funded research project on intra-EU mobility that aimed to explore migrants' lived experiences (Growth, Equal Opportunities, Migration and Markets [GEMM] project). The analysis is based on 240 in-depth interviews carried out between November 2016 and June 2017 by national research teams based in Italy, Spain, Bulgaria and Romania. As explained by the introduction of this thematic issue, the fieldwork included 160 interviews with Italian and Spanish migrants in the UK and Germany and with Bulgarian and Romanian migrants in the UK, Germany, Italy and Spain; 40 interviews concerned potential migrants, i.e., people who decided to move abroad from the four countries. Another 40 interviews involved experts working in employment agencies (either public or private).

Respondents who have already migrated were asked to describe how they had prepared their departure, while prospective migrants explained what they were doing in order to get ready to leave their country in the near future. The interviews have been recorded, transcribed and analysed using MAXQDA software for qualitative analysis. The respondents were equally divided between men and women. One-third was low-skilled working (or willing to work) in construction, domestic care, retail and services; two-thirds were high-skilled working in finance, ICT, construction and health. Nurses can be considered medium-skilled and, in our analysis, were taken into consideration together with the low-skilled migrants. The sample is quite large, but it is distributed among four countries of origin/destination and differentiated by gender, industry and skill level. Given the lack of literature on the preparation for migration, our analysis had mainly an explorative goal. In some cases, we compared the experiences of migrants, highlighting differences linked to the home country or the skill level, and stressing industry specificities. In other cases, results cannot be differentiated along such dimensions and were analysed from a more general perspective. For more details about the methodology and the sample, see the introduction of the thematic issue and the research project website (http://gemm2020.eu).

\section{Lived Experiences of Preparation for Departure}

As mentioned, the article has shed light on the migrants' lived experiences of the preparation phase, i.e., how they prepared for the departure after having decided to move abroad. In some cases, tools and preparation strategies of high-skilled people seemed to be very different from those of medium and low-skilled ones. In other cases, similar tools are used by high and low-skilled people in different ways. Some other differences are linked to the country of origin or to the industry. On the other hand, as we will describe in the last section, there are also some issues that seem common to our respondents, independent from the skill level, the country of origin and the industry. Notwithstanding some overlapping, from an analytical point of view, it seemed helpful to start presenting our findings, stressing the differences between medium/low and high-skilled respondents (the distinction between high and medium/low-skilled respondents is based on the GEMM research design and refers to their occupations, or to the jobs they are looking for). The last subsection will highlight the characteristics of the preparation phase that do not differ by skill level.

\subsection{Medium and Low-Skilled People Preparing to Move Abroad}

The interviews highlighted that, during the preparation phase, it is quite common among medium and lowskilled people to use social networks in order to gather information on the destination. This practice was predominantly recurrent among Romanian and Bulgarian low-skilled workers of our sample, mainly employed in the construction or domestic sectors in Italy and Spain. They usually refer to their strong social ties such as family members, kin, and friends (Granovetter, 1974). These people represent an important source of social capital (Coleman, 1990) that migrant workers can also 'activate' as a protective net in case of difficulties upon arrival. New Intra-EU migrants, as other migrants, opt to move to places where they already have social ties or they think that it is easier to build social ties (for instance, in cities where the national community is numerous; Massey et al., 1998). Moreover, social networks play an increasing role in specific sectors (for instance, the construction sector) where recruitment is often based on networks and informal working practices.

Weak social ties are also an important source of information for medium and low-skilled people. Different from the previously cited low-skilled workers moving from Romania and Bulgaria to Italy and Spain, Italians and Spaniards working as clerks and in the hospitality sector explained that information before arrival was mainly collected through social media (for instance, Facebook groups) or by activating weak ties (for instance, excolleagues) in the destination country. A possible explanation of this difference among our respondents is linked to the industry's specifics: Finding employment as a bar- 
tender or clerk may not depend on network-based hiring, and job seekers may apply for a job by either going directly to the workplace or responding to (online) advertisements. Social media can thus provide very useful information to people who want to migrate and enable them to create new social ties.

Moreover, for prospective migrants, reading stories or collecting lived experiences of migration through social media strengthens their confidence. Life fragments of those who have already emigrated shared on social media reinforce the idea that there are 'real' opportunities for success and that the choice to migrate can be easier than expected:

I visited webpages or web-communities concerning Italians in London, where you can find very useful information or where it is possible to help each other, to find somebody who can give you a hand. You can find job advertisements too....This kind of information is a benefit for people who decide to go abroad. (Italian, waiter/electrician in London, male)

Another dimension that plays an important role has to do with the continuity over time of specific national groups' migration flows. Intra-EU migration flows from Central and East European countries started from the early 1990s onward, after the fall of the Iron Curtain (King, 2018). Thus, it can be argued that the continuity of these flows during almost the last two decades may imply the perpetuation of migrant networks; and vice versa. With regard to migration flows of Italians and Spaniards though, there was a discontinuity and, as a result, migrant networks have become considerably weaker, if not dissolved in many cases (Dimitriadis et al., 2019).

Preparation before departure usually includes learning the language of the destination country. Linguistic preparation allows not only a smooth entry into the labour market, but also constitutes a factor facilitating integration in the receiving society. Notwithstanding its importance, learning the language of the destination country before departure was not considered an important action by the medium/low-skilled people we interviewed. Specifically, language competencies tend to be considered as non-essential skills for low-skilled Romanian and Bulgarian job seekers in the construction or domestic sectors. In these cases, many respondents entered the labour market of the destination country with limited knowledge of the local language:

If they offer me [a job], right, I repeat myself I shall learn to speak Spanish. It's not something impossible. (Bulgarian, IT specialist planning to move to Spain, male)

Similar findings concern Italian and Spanish migrants who found employment in the hospitality sector in London and Berlin. Generally, most who had limited knowledge of the local language found jobs in Italian/
Spanish style restaurants or cafes owned or managed by fellow nationals (see also, Lulle, Morosanu, \& King, 2018). In this case, they were able to find employment and learn the local language or improve their linguistic skills at work. At the same time, however, several respondents were aware of the risks of working among co-nationals, as it frequently limits progress in local language acquisition and social and cultural integration in the destination.

The empirical research highlighted some important aspects concerning the administrative procedures that migrants can complete before departure. These include applying for recognition of education titles as well as the procedures to open a bank account or to acquire a tax number and health insurance. Notwithstanding, the lived experiences of migrants showed that these procedures might take a long time and constitute a barrier to access job opportunities when migrants arrive in the host country, the medium and low-skilled people we interviewed rarely spent time on these issues before departure. In all four national cases, respondents often claimed that they collected all necessary documents after arrival. However, an interesting difference regards Romanian and Bulgarian low-skilled workers migrating to Italy and Spain: after their arrival, they usually relied on their migrant network to complete all of the required documentation. As said previously, since their migration is perpetuated through migration networks, newcomers from Bulgaria and Romania seem to resort more to the support of relatives and friends, whereas Italians and Spanish migrants reported doing so less frequently. A Romanian respondent, for instance, pointed out that his relatives working in Italy carried out all the administrative arrangements he needed. Consequently, he did not personally undertake any administrative measures, nor did he use any official channels to find a job once arrived in Italy.

Moreover, the interviews with Bulgarian and Romanian medium or low-skilled people highlighted a certain scepticism vis-à-vis public institutions, which deterred them from contacting public offices before departure. The generally negative perceptions of public authorities seemed to urge some interviewed Bulgarian low-skilled workers to postpone administrative procedures after arrival in order to avoid dealing with the Bulgarian bureaucracy:

I have a passport, an identity card. What should I look for there? Am I a criminal to go signing there? [In Italy] everything happens faster. Now if you go to our embassy [it is much slower]. That's what we Bulgarians are. Doesn't matter where we are, it is as Bulgarians....They simply don't know how they should contact with people. They are always cold; they don't explain to you, you have to guess. (Bulgarian construction worker in Madrid, male)

This general trend concerning the preparation of medium and low-skilled people did not concern people working or looking for a job in the health sector. In this 
case, both the recruitment process and the preparation phase were very structured thanks to the role of some institutional actors as private employment agencies. Indeed, they did not only match the work demand and supply of health professionals, but they also provided information and services to prospective migrants. Such information regarded employment conditions in the destination country, the workplaces' organisational culture, and advice concerning the settlement in the new context. Moreover, health professionals who moved abroad through labour intermediaries took specific preparatory steps that include language courses, support for bureaucratic and administrative procedures and, in some cases, housing services:

There was a fair in Rome where all these German companies had job offers. Whoever was interested could take part in a meeting in Rome: Basically, it was a cognitive interview where all companies came and offered jobs, showing and explaining what they wanted. They talked with the candidates and they decided if the candidate was more appropriate for caring services at home, or in hospital, etc. I did this interview for the hospital where I currently work. I was chosen in short by the two representatives of the hospital who were present during the meeting in Rome, so once I was chosen I started the German course, and during the course I had already signed the contract that provided six months of trial; after those six months the contract became open-ended. (Italian nurse in Hamburg, female)

\subsection{High Skilled People Facing the Preparation Phase}

The fieldwork has highlighted a perception of a 'smooth' mobility across European countries, more for high-skilled people than for the low-skilled ones: In several cases, high-skilled respondents working or seeking a job in finance, IT, health and construction did not seem to be worried about possible obstacles in their migration paths. Anyway, this category of respondents also prepared their departure, even if, in many cases, during the interviews, they put in the background what they really took as preparatory steps.

During the preparation phase, high-skilled people seemed to use 'weak ties' or the internet in a more extensive and 'targeted' way in comparison to the low-skilled respondents. What is of great relevance here is the use of social media such as Facebook, which allows the reactivation of 'latent' ties (old friends or ex-colleagues), or the developing of new contacts among users. Such contacts circulate information that helps potential migrants to know what they may expect upon arrival: how to find a job but also where to find accommodation or the living costs in the new context. For instance, the majority of highly skilled respondents claimed that they contacted acquaintances, who had emigrated recently, through social media or collected information through Facebook groups such as 'Italians in London,' or more employmentoriented, such as 'Spanish Doctors in the UK.'

With regard to the language, a basic knowledge of English is quite widespread in all the four countries we considered, but we found several cases of high-skilled workers who moved to Germany without any preparation concerning the German language, relying only on their English knowledge. In this respect, of great relevance is the sector in which these migrants are employed (Ryan \& Mulholland, 2014) as well as the particularity of Berlin as a global city. More precisely, high-skilled workers in IT or finance may work exclusively in English and, more generally, many respondents consider Berlin as an international city in which one can 'get by' without speaking German:

I have been living here for five and a half years...and I do not speak German. I understand I know a few words....But I don't need it! That's the problem and the advantage of this city: the language is not needed. There are no problems in my sector. At the supermarket all speak English, that is to say in Berlin, English is widely spoken. (Italian IT technician in Berlin, male)

This attitude was also confirmed after some years spent in Germany. With this regard, some respondents were aware of the cost of working in English-language 'bubbles' when it came to social integration. For instance, a Spanish investment fund manager in Berlin regretted that:

I speak very bad German, I mean, I can't even say that I speak German. I can order a coffee; I can understand a few things, but no.... It's very difficult with my job to practice the language because I spend my days working in English. My work is focused on the Englishspeaking world. Also, [it doesn't help] that whenever I try to speak to someone in German, they switch to English. (Spanish finance analyst in Berlin, male)

Besides the positive perceptions of the high-skilled respondents about the freedom and the easiness of intraEU mobility, the research also highlighted some obstacles our respondents faced when they dealt with some bureaucratic procedures. They referred, for instance, to the recognition procedures of educational titles they attained in the departure country. In general, the process of recognition takes time, whether it is done before leaving or afterwards. As regards people working in the health sector, highly skilled as well as medium/lowskilled ones, the fieldwork highlighted that the role of employment agencies, which operate as intermediaries, can be crucial in order to make these procedures faster and smoother.

\subsection{When the Preparation Phase Is 'Squeezed'}

Some respondents, both high and low-skilled, did not report being 'prepared' before their departure. They col- 
lected little information on their destination, they did not make any effort in improving their knowledge of the local language and they did not seek a job before migrating. They often recounted that they had no idea of where to go while they considered leaving their home country. For instance, Romanians and Bulgarians who aimed to work as construction or domestic workers, when asked about the steps they have already taken preparing for departure, answered: "I bought the airplane tickets." According to an employment agency's counsellor, many Bulgarian people, after their country's admission into the EU, assumed that the identity card is all one needs to come and start working in another country.

The study sheds light on some factors that can help to explain this 'shortening' of the preparation phase. First, participation in some exchange programs-such as Erasmus for university students-had a significant impact on the attitudes of respondents concerning the preparation phase. Indeed, the idea of freedom of movement across European countries, which these programs convey, is not only formal: People have the opportunity to spend periods of their lives in other countries and therefore to know them better than when travelling as tourists. Many Italian and Spanish respondents had lived in various European countries, mainly through European exchange programmes. This was most common for the high-skilled workers of our sample, such as doctors and financial experts. Romanian and Bulgarian graduates participate less frequently to the Erasmus program, but they often 'compensated' for the lack of international mobility programs with their networks of already emigrated co-nationals. For instance, it was common among Romanians to visit relatives and friends already residing in the destination country before they decided to migrate. Only a few Italians or Spaniards reported similar stories. This difference is explained by the already mentioned different migration history of these countries.

Another factor that can explain why our respondents faced the decision to migrate with little preparation is the spatial proximity between home and destination country. This element makes the decision to emigrate more easily reversible:

Two young guys from my town told me: "We are going to London to look for work, if you want, you can come with us." And so, I had money saved and I told myself: "They know English....And, look, I've visited London twice, so I know the city a bit, although I've only been on holidays....l'll go, l'll see how it goes for a month and if I don't find anything [a job], I'll just come back [to Spain]." (Spanish construction worker in London, male)

Finally, the analysis of interviews showed the presence of some shared social imaginaries that may have contributed to 'squeeze' the preparation phase. They are over-simplified representations of both countries of de- parture and destination. With regard to the latter point, they refer to some countries but, more specifically, to two big cities: Berlin and London. The meanings connected to these imaginaries-which are extremely positive for the destination and very negative for the countries of departure-reinforced the prevalent perception of smooth mobility across European countries, discarding the need for any specific preparation.

Concerning the destination places, the fieldwork showed that some stereotyped images of Italy, Spain and the UK seemed to be still significant factors that can affect the preparation phase of Bulgarians and Romanian migrants. Specifically, these representations strengthened the perception of cultural proximities or similar attitudes, which can justify less attention to the preparation phase. Moreover, in these cases, common imaginaries are built on elements that frequently derive from old movies and 'old-fashioned' representations of the countries of destination. For instance, several Bulgarian respondents - who arrived in Italy in the 1990s or early 2000 s-claimed that what they knew about Italy was based on Fellini's movies; for them, Italians were people who talk loudly and gesture and who hang laundry to dry from balconies. In the same way, perceptions of the UK directly referred to romantic and Victorian novels which Bulgarian respondents became familiar with through English-language textbooks. These imaginaries seemed a sort of 'crystallisation' of those shared by prospective migrants of previous decades when access to more practical and in-depth information on countries of destination was less readily available.

For this reason, we would have expected a lower diffusion of stereotyped images among current prospective migrants and among migrants from countries with a migration history characterised by a discontinuity in recent years, like Italy and Spain. However, the fieldwork did not confirm our expectations. Indeed, many respondents seemed to be enchanted by 'myths' and common positive narratives mainly concerning Berlin and London. This idea resonates not only with migrants already resident abroad but also with those who are planning to move. The two cities have been often stated as urban areas with dynamic labour markets, in which talent and ability are recognised and valued, but also as cities with a vibrant cultural life:

Apart from architects, if we are talking about other graduates with a higher secondary school or technical degree and not a university degree, then we are talking about England, there is always the myth of London, even if I [will be working] as a pizza [delivery] man; but I want to go to London. (Italian receptionist in London, female)

Because Berlin is a trendy city. It is so fashionable now.... How can I explain? It's an amazing city. (Italian civil engineer in Berlin, male) 
England is a challenge that is interesting for me and for us because here is the market, everybody wants to be in London, everyone wants to do business there. (Bulgarian marketing representative in London, female)

The study showed that the role of social media in sharing over-simplified representations of the destination places and common imaginaries was relevant. For instance, many respondents drew attention to the fact that 'so many' of their classmates or work colleagues had applied to foreign universities or been hired by foreign employers and that this had encouraged them to follow their example. These factors seem to operate almost at the margins of consciousness. A Spanish respondent, who moved to Berlin, referring to his short preparation phase highlighted that he had friends and family members living in different European countries:

I think that all of that was 'in the air.' My sister had also left [Spain] a year and a half before me...for London....So, obviously, I was thinking [in terms of] "my sister has left and she is doing well." That was also an incentive to [leave]. (Spain housekeeper in Berlin, male)

In this case, the respondent did not follow his sister to London, he did not use his 'strong tie' to collect information about London, but he 'used' the migration experience of his sister on a more symbolic level in order to better translate his idea of moving to Berlin into a concrete plan. Similarly, several Italian respondents expressed their interest in specific destinations in ways that evoked more the role of 'contagion' than some economic rationality (Abrutyn \& Mueller, 2014). Indeed, they talked of London as a 'cool' destination and referred to the fact that 'so many Italians have flocked there':

Basically, I was curious, because everyone speaks of the English model and everyone tries to take it as an example because it seems to work because it is efficient....Everyone went to London and so I do too. (Italian cook in London, male)

The shrinking of the preparation steps was also due to some (negative) shared representations of the departure countries. They seemed to contribute to the spreading of the perception of the exit option as a matter of urgency and as a not-too-risky choice. Indeed, the recent economic crisis has increased the negative perceptions of the departure countries (Bulgaria, Italy, Romania and Spain), in terms of job opportunities, working conditions, salaries, meritocracy and the diffusion of corruption. The majority of respondents showed few-or no-expectations for the future of their country, both in economic and social terms. In this case, public and media discourse played an important role in building and sharing some prevalent narratives. The topic of emigration has been sensationalised in all four countries and has sparked disproportionately high levels of press, television and social media coverage (Bygnes \& Flipo, 2017; Caneva, 2016). Notwithstanding, the direct consequences of the crisis were not always lived as personal experiences of unemployment. Our respondents were indirectly, yet constantly reminded through images and reports in the media of the deep economic problems in their countries. For instance, a low-skilled Spanish respondent-fed-up of working in the informal sector and recently dropped out of his professional training programme-was asked whether he had considered exploring employment options in other parts of the country instead of directly searching abroad and he answered:

No, because Spain is hopeless. I could see how things were going on TV. It [Spain] was in very bad shape three years ago. (Spanish receptionist in London, male)

In the Bulgarian and Romanian cases, a general feeling of disillusion, often targeting rather abstract notions of 'the state,' 'the mentality,' and 'moral breakdown,' seemed to be prevalent, emphasising the 'need' to emigrate. Bygnes and Flipo (2017), in their research on Romanian emigrants in Spain, highlighted similar findings, noting a great deal of distrust in Romania's politicians and institutions. In general, the level of media saturation may have had a catalysing effect for the translation of aspirations for migration to concrete decisions.

\section{Conclusion}

The analysis of the preparation phase, which stays between the decision to migrate and the departure, highlighted some relevant aspects of the lived experiences and the perceptions that migrants and prospective migrants have of intra-EU mobility. The steps they decide to take, and the expectations they have, reveal how they decide to convert the decision to depart into empirical actions and strategies and how they approach the migration. For instance, as the analysis of the empirical data has shown, important actions in terms of the improvement of language skills and the fulfilment of administrative procedures can be taken before leaving the country of origin; but, in several cases, people do not consider them necessary, even if this decision can delay or even impede the search for a job and the settlement in the destination country.

The fieldwork has shed light on some relevant differences between high and medium/low-skilled migrants in terms of actions, tools, and attitudes. These differences were explained not only by their human capital but also by some specific social factors. According to the skill level, social networks were used in different ways, as they can play a different role in collecting information. Experiences abroad helped in facing the preparation phase: Highly-educated people had them thanks to university exchange programs, while transnational social networks played a particularly relevant role for less- 
educated migrants from Bulgaria and Romania who were used to visiting friends and relatives that live in other European countries. Migration history of the country of origin, therefore, matters in this regard and explains some differences between Bulgarian and Romanian migrants, on the one hand, and Spanish and Italian migrants on the other.

Social media arose as a very important tool to collect information on the destination countries, but it is used in different ways by high-skilled migrants-where a more functional use prevailed-and by medium and low-skilled ones. In general, informal ways to collect information were predominant, except for people working or looking for a job in the health sector, where private employment agencies had a relevant role in the preparation phase. This specific case put to the fore the possibilities of action for institutional actors, either public or private, supporting prospective migrants and guiding their preparation for departure.

With small differences linked to the skill level, the study showed that most of the respondents, while preparing their departure, perceived the EU as a space where they are free to move. The fragments of life we collected about the preparation steps to migrate highlighted that this process is characterised by some aspects of 'smoothness' or 'fluidity,' at least in the migrants' perceptions. The idea of freedom of movement within the EU seems thus strongly embedded among the respondents who, in some cases, under-evaluated the difficulties and the obstacles to mobility and decided to leave their home country more light-heartedly than expected. Moreover, the analysis put to the fore the pivotal role of social imaginaries about the origin and destination countries. Focusing on the preparation phase, we highlighted in particular how some positive myths about Berlin and London affected the perceptions of the destination and how the 'contagion' effect can take place in this regard. At the same time, over-simplified representations of studied countries of origin can contribute to squeezing the preparation phase, emphasising the urgency to migrate and the migrants' bewilderment facing the first steps of their choice.

Some policy implications can be listed very briefly in conclusion. First, empirical evidence suggests that policymakers should focus on the city factors that may attract European migrants. On the other hand, they need to be aware of the consequences that negative expectations concerning the economic and political situation of a country can have in terms of migration outflows. Second, the fieldwork has shown that investment in foreign language teaching in public schools and long-life learning programs could limit the difficulties that new migrants may face in the European labour market. A third implication concerns the need for homogenisation of professional training across European countries. It could further facilitate mobility since bureaucratic requirements within specific sectors currently represent a barrier to European migrants' insertion in the European labour markets.

\section{Acknowledgments}

This research has been supported by funding from the European Commission (GEMM Research ProjectGrant Number H2O20 649255). The authors wish to thank Iraklis Dimitriadis, Ivana Fellini, Fabio Quassoli, and Maricia Fischer-Souan for the fruitful discussions about the research findings and the anonymous reviewers for their suggestions.

\section{Conflict of Interests}

The authors declare no conflict of interests.

\section{References}

Abrutyn, S., \& Mueller, A. S. (2014). Reconsidering Durkheim's assessment of trade: Formalizing a Tardian theory of imitation, contagion, and suicide suggestion. Sociological Forum, 29(3), 698-719.

Appadurai, A. (1996). Modernity at large: Cultural dimensions of globalization. Minneapolis, MN: University of Minnesota Press.

Bartolini, L., Gropas, R., \& Triandafyllidou, A. (2017). Drivers of highly skilled mobility from Southern Europe: Escaping the crisis and emancipating oneself. Journal of Ethnic and Migration Studies, 43(4), 652-673.

Bauman, Z. (2000). Liquid modernity. Cambridge: Polity Press.

Benson, M. (2012). How culturally significant imaginings are translated into lifestyle migration. Journal of Ethnic and Migration Studies, 38(10), 1681-1696.

Benson, M., \& O'Reilly, K. (2009). Migration and the search for a better way of life: A critical exploration of lifestyle migration. The Sociological Review, 57(4), 608-625.

Benson, M., \& Osbaldiston, N. (Eds.). (2014). Understanding lifestyle migration: Theoretical approaches to migration and the quest for a better way of life. Basingstoke: Palgrave.

Bygnes, S., \& Flipo, A. (2017). Political motivations for intra-European migration. Acta Sociologica, 60(3), 199-212.

Caneva, E. (2016). Giovani italiani che emigrano: Percorsi di vita inediti all'epoca della crisi economica globale [Young Italians who emigrate: New ways of life at the time of the global economic crisis]. Mondi Migranti, 3, 79-93.

Castellani, S. (2018). Scivolando verso il basso: L'inserimento lavorativo dei nuovi migranti italiani e spagnoli in Germania durante la crisi economica [Sliding down: The employment of new Italian and Spanish migrants in Germany during the economic crisis]. Sociologia del Lavoro, 149, 77-93.

Castoriadis, C. (1997). The imaginary institution of society. Cambridge: Polity Press.

Coleman, J. (1990). Foundations of social theory. Cam- 
bridge, MA: The Belknap Press of Harvard University Press.

Dekker, R., \& Engbersen, G. (2012). How social media transform migrant networks and facilitate migration (IMI Working Paper No. 64). Oxford: International Migration Institute.

Dimitriadis, I., Fullin, G., \& Fischer-Souan, M. (2019). Great expectations? Young Southern Europeans emigrating in times of crisis. Mondi Migranti, 3, 137-162.

Engbersen, G. (2012). Migration transitions in an era of liquid migration. In M. Okolski (Ed.), European immigrations: Trends, structures and policy implications (pp. 91-105). Amsterdam: Amsterdam University Press.

Favell, A. (2008). Eurostars and Eurocities: Free movement and mobility in an integrating Europe. Oxford: Blackwell.

Favell, A., \& Recchi, E. (Eds.). (2009). Pioneers of European integration: Citizenship and mobility in the EU. Cheltenham: Edward Elgar Publishing.

Granovetter, M. (1974). Getting a job: A study of contacts and careers. Cambridge, MA: Harvard University Press.

Haythornthwaite, C. (2002). Strong, weak, and latent ties and the impact of new media. The Information Society, 18(5), 385-401.

King, R. (2012). Theories and typologies of migration: An overview and a primer (Willy Brandt Series of Working Papers in International Migration and Ethnic Relations, No. 3). Malmoe: Malmoe Institute for Studies of Migration, Diversity and Welfare. Retrieved from https://www.mah.se/upload/ Forskningscentrum/MIM/WB/WB\%203.12.pdf

King, R. (2018). Theorising new European youth mobilities. Population, Space and Place, 24(1), 1-12.

Lillie, N., \& Simola, A. (2016). The crisis of free movement in the European Union. Mondi Migranti, 2016(3), 7-20.

Lulle, A., Morosanu, L., \& King, R. (2018). And then came Brexit: Experiences and future plans of young EU migrants in the London region. Population, Space and
Place, 24(1). https://doi.org/10.1002/psp.2122

Maile, S., \& Griffiths, D. (2012). Longings for Berlin: Exploring the workings of the psycho-social imaginary in British migration. Journal of Psycho-Social Studies, 6(1), 30-53.

Mapelli, G. (2019). The identity construction of migrants on Facebook. Languages, 4(3), 1-17.

Massey, D. S., Arango, J., Hugo, G., Kouaouchi, A., Pellegrino, A., \& Taylor, J. E. (1998). Worlds in motion: Understanding international migration at the end of the millennium. New York, NY: Oxford University Press.

Menjivar, C. (2000). Fragmented ties. Berkeley, CA: University of California Press.

O'Reilly, K. (2014). The role of the social imaginary in lifestyle migration: Employing the ontology of practice theory. In M. Benson \& N. Osbaldiston (Eds.), Understanding lifestyle migration: Theoretical approaches to migration and the quest for a better way of life (pp. 211-234). Basingstoke: Palgrave.

Pessar, P., \& Mahler, S. (2002). Transnational migration: Bringing gender. International Migration Review, 37(3), 812-846.

Portes, A., \& Sensenbrenner, J. (1993). Embeddedness and immigration. American Journal of Sociology, 98(6), 1320-1350.

Recchi, E. (2013). Senza frontiere: La libera circolazione delle persone in Europa [Without borders: The free movement of people in Europe]. Bologna: II Mulino.

Ryan, L., \& Mulholland, J. (2014). Wives are the route to social life: An analysis of family life and networking amongst highly skilled migrants in London. Sociology, 48(2), 251-267.

Salazar, N. B. (2011). The power of imagination in transnational mobilities. Identities, 18(6), 576-598.

Smith, M. P., \& Favell, A. (Eds.). (2006). The human face of global mobility. New Brunswick, NJ: Transaction.

Tarde, G. (2010). On communication and social influence. Chicago, IL: University of Chicago Press.

Taylor, C. (2004). Modern social imaginaries. Durham, NC: Duke University Press.

\section{About the Authors}

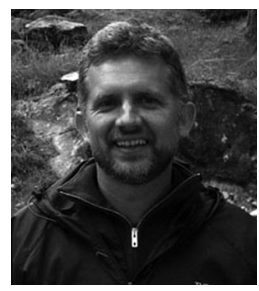

Diego Coletto is Associate Professor of Economic Sociology and Sociology of Work at the Department of Sociology and Social Research, University of Milano-Bicocca, Milan (Italy). He holds a degree in Political Sciences and a PhD in Economic Sociology. His main research interests are the informal economy, street-level bureaucracy, urban ethnography, and employment relations. He has participated in several national and international research projects. He published two books and various articles in national and international journals among which the International Journal of Sociology and Social Policy, Review of Economics and Institutions, Etnografia e Ricerca Qualitativa, Rassegna Italiana di Sociologia.

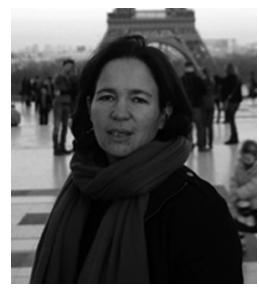

Giovanna Fullin is Associate Professor in Economic Sociology at the University of Milan-Bicocca. She holds a degree in Economics and a PhD in Economic Sociology. Her main interests cover the labour market structure and trends, work conditions in the service sector, retail work, and immigrants in the labour market. She has participated in several international research projects. She has published several articles in national and international journals, among which Work, Employment \& Society, International Migration, Work and Occupations, European Journal of Employment Relations, International Journal of Comparative Sociology. 